\title{
The Impact of a History of Sexual Abuse on Health: Data from a Self- Reported Questionnaire from a Sample of French Victims
}

Jean-Louis Thomas ${ }^{1}$, Violaine Guerin ${ }^{1 *}$, Pierre Levy ${ }^{2}$, Maria Carette ${ }^{1}$, Nathalie Regensberg de Andreis ${ }^{1}$ and Philippe Lacrosse ${ }^{1}$

${ }^{1}$ Departement Medical, Stop aux Violences Sexuelles (SVS), Paris, France

${ }^{2}$ Departement de Sante Publique et Unité de Neurophysiologie Clinique, Hôpital Tenon (AP-HP), Paris, France

"Corresponding author: Violaine Guerin, Département Medical, Stop aux Violences Sexuelles (SVS), Paris, France, Tel: +33145722505; E-mail: dr.v.guerin2@orange.fr

Received date: November 06, 2017, Accepted date: November 13, 2017, Published date: November 15, 2017

Copyright: ( 2017 Thomas JL, et al. This is an open-access article distributed under the terms of the Creative Commons Attribution License, which permits unrestricted use, distribution, and reproduction in any medium, provided the original author and source are credited.

\begin{abstract}
Objective: This study aimed to assess the connection between sexual abuse and self-reported lifetime physical and psychiatric disorders.

Subjects and Method: Samples of 178 French subjects (170 women and 18 men) who have been sexually abused have agreed to answer a computerized questionnaire and give the characteristics of their aggression and the physical and psychiatric pathologies they suffered afterwards. They also reported symptoms of anxiety and depression using the 14-item Hospital Anxiety and Depression (HAD) scale. Reported disorders were grouped by system organ class. $x^{2}$ test or exact test of Fisher was used to test association of main characteristics of sexual abuse (type and duration of abuse, multiple/single assault and perpetrator) with each item of medical history.

Results: $83 \%$ of respondents had experienced several sexual assaults, with a first assault occurring mainly during childhood and adolescence. The average length of the sexual abuse period was 2.4 times longer in women, compared to men (9.2 vs. 3.8 years). Most frequently alleged types of abuse were touching (85.5\%) and rape $(76.6 \%)$. The mean age of disclosure of sexual violence was approximately 21 years and the average time between the first abuse and disclosure about 12 years. The most frequent reported physical disorders were chronic pain, allergic, dermatological and gynaecological disorders, and surprisingly ENT disorders. There was in the sample a high prevalence of depression, sleep disorders and suicide attempts. At the time of the investigation the mean HAD scores were $7.0+4.7$ and $11.7+4.6$ for depression and anxiety respectively. Most reported disorders were significantly correlated with the severity of the sexual abuse (rape, duration, number of assaults and/or perpetrators). It was also shown that the delay of disclosure was significantly longer for victims whose first attack occurred when they were younger.
\end{abstract}

Conclusion: A history of sexual abuse is associated with a high prevalence of multiple physical and psychiatric disorders at rates comparable to those found in previously published studies.

Keywords: Sexual abuse; Rape; Health status; Pathological conditions; Mental disorders; Chronic pain; Depression; Suicide; Hypersensitivity

\section{Introduction}

There is an increasing number of studies and papers on the impact of sexual abuse on health. Several studies have focused on the long term effects of sexual violence that may occur at a distance from the initial trauma throughout the life of the victim. It is well established that child sexual abuse, like other forms of mistreatment, is associated with psychiatric and behavioral disorders such as depression, personality disorders, eating disorders, substance abuse [1-4]. The prevalence of chronic pain is also increased among victims, whether it is musculoskeletal or pelvic pain and headache [5-10]. The consequences of sexual violence on physical health are less well known; nevertheless some epidemiological studies have shown that victims of sexual abuse during childhood have a significantly increased risk of developing physical pathologies, such as neurological, gastrointestinal, metabolic and cardiovascular disorders in the adult age [11-14].
However the majority of published studies on health status of adults with a history of sexual abuse were performed in North America or Scandinavian countries. There is little available data from France on the consequences of sexual abuse. This study presents the data obtained from French victims asked by their doctor to answer a questionnaire on the violence they suffered and on the state of their health.

\section{Method}

This retrospective study was conducted in France in 2014-2015 by the association Stop Sexual Violence and was declared to the "Commission Nationale de l'Informatique et des Libertés". Participants included both men and women, victims of sexual violence, who had been approached by their physician when attending a medical appointment. They were volunteers, who signed a written informed consent and received a link by email and a code to answer an anonymous computer-assisted questionnaire by text message.

The questionnaire written in French assessed sociodemographic data of victims and characteristics of the sexual abuse of which they 
Citation: Thomas JT, Guérin V, Lévy P, Carette M, de Andreis NR, et al. (2017) The Impact of a History of Sexual Abuse on Health: Data from a

Page 2 of 8

had suffered, i.e. age at the first aggression, type and duration of the sexual violence, single or multiple assaults, gender and number of abusers, age at the disclosure. They also reported their health history using a yes/no format as to whether or not they were subjected to physical psychiatric and surgical events, had a history of smoking, alcohol and drug use, existence of chronic pain and health care use. Participants also reported symptoms of anxiety and depression using the 14-item Hospital Anxiety and Depression (HAD) scale with 7 items forming an anxiety subscale and 7 items forming a depression subscale [15].

\section{Data analysis}

Mean sociodemographic, medical and sexual abuse data was calculated and evaluated from data collected in the computer-assisted questionnaire personally filled out by each voluntary participant.

Correlation between age of the first aggression and characteristics of sexual abuse was tested using Mann-Whitney $U$ test (type of abuse, multiple/single assault and perpetrator) or Spearman test (abuse duration, age and delay of disclosure).

$\chi^{2}$ test or Exact test of Fisher was used to test association of main characteristics of sexual abuse (type and duration of abuse, multiple/ single assault and perpetrator) had with each item of medical history; for this analysis, reported pathologies were grouped by system organ class. The significance level was 0.05 . Statview 5.0 was used.

\section{Results}

188 subjects (170 women and 18 men), who had been abused, agreed to complete the questionnaire. Participants, of all socioprofessional categories, ranged in age from 5 to 77 with a mean age of $42.6(\mathrm{SD}=12.0)$ years.

Demographic characteristics are given in Table 1.

\begin{tabular}{|c|c|c|c|}
\hline Characteristics & Total $(\mathrm{N}=188)$ & Women $(\mathrm{N}=170)$ & Men $(\mathrm{N}=18)$ \\
\hline Age, mean (SD) years & $42.6+11.96$ & $42.4+12.22$ & $44.1+9.22$ \\
\hline \multicolumn{4}{|l|}{ Marital status (\%) } \\
\hline Married & 35 & 32 & 61 \\
\hline Cohabiting & 21 & 23 & 0 \\
\hline Divorced/separated & 28 & 29 & 22 \\
\hline Never married & 16 & 16 & 17 \\
\hline
\end{tabular}

Table 1: Demographic characteristics of subjects.

\section{History of sexual abuse}

Table 2 summarizes the sexual abuse histories of responders. A majority of them (83.3\%) had experienced several sexual assaults, and the mean duration of the sexual abuse period was 2.4 times longer in women, than in men (9.2 vs. 3.8 years). Most frequently alleged types of abuse were touching $(85.5 \%)$ and rape $(76.6 \%)$.

\begin{tabular}{|c|c|c|c|}
\hline Characteristics & Total $(\mathrm{N}=\mathbf{1 8 8})$ & Women $(\mathrm{N}=170)$ & Men $(\mathrm{N}=18)$ \\
\hline \multicolumn{4}{|l|}{ Number of abuse (\%) } \\
\hline One & 16.7 & 16 & 23.5 \\
\hline Several & 83.3 & 84 & 76.5 \\
\hline Duration of sexual abuse mean (SD) [range] years & $8.7(10.61)[0-60]$ & $9.2(11.00)[0-60]$ & $3.8(3.10)[1-10]$ \\
\hline \multicolumn{4}{|l|}{ Types of sexual abuse (\%) } \\
\hline Rape & 76.8 & 76.5 & 77.8 \\
\hline Oral & 45 & 44 & 53 \\
\hline Rectal & 28 & 26 & 53 \\
\hline Vaginal & - & 62 & - \\
\hline Touch & 85.5 & 86.4 & 76.4 \\
\hline Sex & 75 & 75 & 76 \\
\hline Rectum & 19 & 18 & 35 \\
\hline
\end{tabular}


Citation: Thomas JT, Guérin V, Lévy P, Carette M, de Andreis NR, et al. (2017) The Impact of a History of Sexual Abuse on Health: Data from a Self-Reported Questionnaire from a Sample of French Victims. J Gen Pract (Los Angel) 5: 340. doi:10.4172/2329-9126.1000340

Page 3 of 8

\begin{tabular}{|l|l|l|l|}
\hline Breast & - & 56 & - \\
\hline Harassment & 40.5 & 41.7 & 29.4 \\
\hline Exhibition & 45.9 & 47.3 & 64.7 \\
\hline Mutilation & 3.2 & 3.6 & 0 \\
\hline
\end{tabular}

Table 2: Characteristics of self-reported sexual abuse.

Characteristics of sexual abusers are shown in Table 3. 55\% of women and $35 \%$ of men were victims of more than one abuser. Perpetrators were only males in $81.2 \%$, only females in $1.6 \%$, and both males and females in $17.2 \%$ of cases. $35 \%$ of sexual abuses reported by participants were extra-familial, $32 \%$ intra-familial and $35 \%$ both intra- and extra-familial (Tables 3 and 4).

\begin{tabular}{|c|c|c|c|}
\hline Characteristics & Total $(\mathrm{N}=188)$ & Women $(\mathrm{N}=170)$ & Men $(\mathrm{N}=18)$ \\
\hline \multicolumn{4}{|l|}{ Number of abusers (\%) } \\
\hline One & 46.8 & 45 & 64.7 \\
\hline Several & 53.2 & 55 & 35.3 \\
\hline \multicolumn{4}{|l|}{ Gender of abusers (\%) } \\
\hline Male only & 81.2 & 79.1 & 82.3 \\
\hline Female only & 1.6 & 1.1 & 5.9 \\
\hline Male and female & 17.2 & 19.8 & 11.8 \\
\hline \multicolumn{4}{|l|}{ Type of abusers (\%) } \\
\hline Intra-familial & 31.7 & 30.8 & 41.2 \\
\hline Extra-familial & 33.3 & 32.5 & 41.2 \\
\hline Intra-and extra-familial & 35 & 36.7 & 17.6 \\
\hline
\end{tabular}

Table 3: Characteristics of sexual abusers.

\begin{tabular}{|c|c|c|c|}
\hline Characteristics & Total $(\mathrm{N}=\mathbf{1 8 8})$ & Women $(\mathrm{N}=170)$ & Men $(\mathrm{N}=18)$ \\
\hline Age at the $1^{\text {st }}$ aggression, mean (SD) years & $9.4(6.74)$ & $9.5(7.00)$ & $8.1(3.08)$ \\
\hline \multicolumn{4}{|l|}{ Occurrence of the $1^{\text {st }}$ aggression (\%) } \\
\hline During childhood ( $<11$ years) & 65.2 & 64.1 & 82.4 \\
\hline During adolescence (11-18 years) & 27.7 & 28.7 & 17.6 \\
\hline During adulthood (>18 years) & 6.5 & 7.2 & 0 \\
\hline \multicolumn{4}{|l|}{ Type of the $1^{\text {st }}$ aggression (\%) } \\
\hline Rape & 41.3 & 40.7 & 47 \\
\hline Touch & 52.7 & 53.9 & 41.2 \\
\hline Harassment & 1.6 & 1.8 & 0 \\
\hline Exhibition & 4.4 & 3.6 & 11.8 \\
\hline
\end{tabular}

Table 4: Characteristics of the first self-reported sexual abuse.

The first sexual assault occurred, mainly during childhood and 53\% of the respondents sexual touching was the first assault; and rape adolescence, at a mean age of 9.4 years, ranging from 5 to 73 years. For for $41 \%$ of them. 
Citation: Thomas JT, Guérin V, Lévy P, Carette M, de Andreis NR, et al. (2017) The Impact of a History of Sexual Abuse on Health: Data from a Self-Reported Questionnaire from a Sample of French Victims. J Gen Pract (Los Angel) 5: 340. doi:10.4172/2329-9126.1000340

Page 4 of 8

For both female and male respondents, the mean age of disclosure of sexual abuse was approximately 21 years
The mean delay between the first abuse and disclosure about 12 years (Table 5).

\begin{tabular}{|l|l|l|}
\hline Number of years, mean (SD), [range] & Total (N=188) & Women (N=170) \\
\hline Age at the disclosure of sexual abuse & $\begin{array}{l}20.8(13.87) \\
{[0-70]}\end{array}$ & $\begin{array}{l}20.7(13.78) \\
{[0-70]}\end{array}$ \\
\hline Delay between 1st aggression and disclosure of sexual abuse & $\begin{array}{l}11.8(14.42) \\
{[6-47]}\end{array}$ & $\begin{array}{l}11.7(14.40) \\
{[0-68]}\end{array}$ \\
\hline
\end{tabular}

Table 5: Timing of sexual abuse disclosure.

\section{Self-reported health disorders}

As shown in Table 6, among the physical disorders, allergies, gynaecological, dermatological and ENT disorders were reported by more than one third of responders of both genders.
Two thirds of the subjects reported chronic pain, abdominal and musculoskeletal pain being the most frequent.

Over $40 \%$ of victims suffered from headaches and migraines (Table $6)$.

\begin{tabular}{|c|c|c|c|}
\hline Characteristics & Total $(\mathrm{N}=188)$ & Women $(\mathrm{N}=170)$ & Men $(\mathrm{N}=18)$ \\
\hline Allergy & 49 & 47 & 65 \\
\hline Gynaecological disorders & - & 45 & - \\
\hline Skin disorders & 45 & 43 & 65 \\
\hline ENT disorders & 35 & 35 & 35 \\
\hline Neurological disorders & 30 & 29 & 41 \\
\hline Renal and urinary disorders & 28 & 29 & 18 \\
\hline Endocrine disorders & 26 & 29 & 0 \\
\hline Musculoskeletal disorders & 25 & 25 & 24 \\
\hline Gastrointestinal disorders & 22 & 22 & 24 \\
\hline Respiratory disorders & 20 & 20 & 18 \\
\hline Chronic pain & 66 & 67 & 59 \\
\hline Abdominal pain & 50 & 50 & 50 \\
\hline Pelvic pain & 25 & 26 & 10 \\
\hline Joint pain & 66 & 67 & 50 \\
\hline Muscle pain & 56 & 57 & 40 \\
\hline Headache & 47 & 47 & 50 \\
\hline Migraine & 43 & 44 & 40 \\
\hline
\end{tabular}

Table 6: Reported physical health disorders (\%).

Mental and behavioural health problems for the group are given in Table 7. Seventy-six of women and $49 \%$ of men have a history of depression. The mean HAD depression score of the group was lower than the mean HAD anxiety score (7.0; SD: 4.7; range: 0-12 vs. 11.7; SD: 4.6; range: 1-12).

Sleep disorders were reported by one in two patients. A history of suicide attempts was reported by $36 \%$ of subjects. The mean number of attempts was 5 (SD: 8.3; range: 1-50).
$51 \%$ of women have a history of bulimia (compared to only $18 \%$ in men). Obesity (BMI $>30 \mathrm{~kg} / \mathrm{m}^{2}$ ) was found only in women, in $14 \%$ of them. The prevalence of addiction to tobacco, alcohol and illicit substances was 32,11 and $22 \%$ respectively.

Two-thirds of women and $41 \%$ of men said they have undertaken a reparation process. $22 \%$ of respondents were hospitalized in the previous year, for an average of 20.3 days for women and 10.7 days for men (Table 7). 
Citation: Thomas JT, Guérin V, Lévy P, Carette M, de Andreis NR, et al. (2017) The Impact of a History of Sexual Abuse on Health: Data from a Self-Reported Questionnaire from a Sample of French Victims. J Gen Pract (Los Angel) 5: 340. doi:10.4172/2329-9126.1000340

Page 5 of 8

\begin{tabular}{|c|c|c|c|}
\hline Characteristics & Total $(\mathrm{N}=188)$ & Women $(\mathrm{N}=170)$ & Men $(\mathrm{N}=18)$ \\
\hline Depressive disorders & 74 & 76 & 59 \\
\hline Sleep disorders & 48 & 49 & 41 \\
\hline Suicide attempt & 36 & 38 & 18 \\
\hline Psychiatric disorders & 33 & 34 & 18 \\
\hline Claustrophobia & 36 & 37 & 29 \\
\hline Self-harm & 31 & 34 & 0 \\
\hline Obsessive-compulsive disorder & 18 & 17 & 24 \\
\hline Bulimia & 48 & 51 & 18 \\
\hline Anorexia & 35 & 37 & 24 \\
\hline Smoking & 32 & 33 & 24 \\
\hline Alcoholism & 11 & 11 & 18 \\
\hline Drug addiction & 22 & 22 & 29 \\
\hline
\end{tabular}

Table 7: Reported psychological health disorders, eating disorders and addictions (\%).

\section{Association between age at the first aggression and characteristics of sexual abuse}

The younger the victim at the moment of the first assault, the longer the duration of the violence $(\mathrm{p}<0.001)$, the greater the number of aggressions $(p<0.03)$ and longer the delay of disclosure $(p<0.0001)$. There was no significant association between the type of abuse and the number of assaults.

\section{Association between characteristics of sexual abuse and medical reported disorders}

As shown in Table 8, rape, but not other types of abuse, was significantly associated with dermatological, gastrointestinal, renal/ urinary, obsession-compulsive and sleep disorders, chronic pain (especially abdominal, pelvic pain, headache and migraine) and suicide attempts.

The latter were also directly correlated with the number of aggressors.

Longer duration of abuse, multiple assaults, multiple perpetrators were significantly associated with both gynaecological and ENT disorders.

Depressive disorders were significantly more frequent in victims of longer violence duration and higher numbers of perpetrators (Table 8).

\begin{tabular}{|c|c|c|c|c|}
\hline Characteristics & Rape & Duration & $\begin{array}{l}\text { Number of assaults } \\
\text { (multiple vs. single) }\end{array}$ & $\begin{array}{l}\text { Number of perpetrators } \\
\text { (multiple vs. single) }\end{array}$ \\
\hline Allergy & ns & ns & ns & ns \\
\hline Gynaecological disorders & ns & $<0.001$ & $<0.01$ & 0.0001 \\
\hline Skin disorders & $<0.02$ & ns & $<0.03$ & ns \\
\hline ENT disorders & ns & $<0.04$ & $<0.05$ & $<0.04$ \\
\hline Neurological disorders & ns & $<0.01$ & ns & ns \\
\hline Renal and urinary disorders & $<0.02$ & ns & $<0.05$ & ns \\
\hline Endocrine disorders & ns & ns & ns & ns \\
\hline Musculoskeletal disorders & ns & ns & ns & $<0.05$ \\
\hline Gastrointestinal disorders & $<0.03$ & ns & ns & ns \\
\hline Respiratory disorders & ns & ns & ns & ns \\
\hline Chronic pain & $<0.05$ & ns & ns & 0.0001 \\
\hline
\end{tabular}


Citation: Thomas JT, Guérin V, Lévy P, Carette M, de Andreis NR, et al. (2017) The Impact of a History of Sexual Abuse on Health: Data from a Self-Reported Questionnaire from a Sample of French Victims. J Gen Pract (Los Angel) 5: 340. doi:10.4172/2329-9126.1000340

Page 6 of 8

\begin{tabular}{|c|c|c|c|c|}
\hline Abdominal pain & $<0.04$ & - & - & - \\
\hline Pelvic pain & $<0.05$ & - & - & $<0.02$ \\
\hline Joint pain & ns & - & - & - \\
\hline Muscle pain & ns & - & - & - \\
\hline Headache & $<0.03$ & - & - & - \\
\hline Migraine & $<0.02$ & - & - & - \\
\hline Depressive disorders & ns & $<0.03$ & ns & $<0.02$ \\
\hline Sleep disorders & $<0.01$ & $<0.02$ & ns & ns \\
\hline Suicide attempt & $<0.05$ & ns & ns & $<0.001$ \\
\hline Psychiatric disorders & ns & $<0.02$ & ns & ns \\
\hline Claustrophobia & ns & ns & ns & ns \\
\hline Self-harm & ns & $<0.04$ & ns & $<0.05$ \\
\hline Obsessive-compulsive disorder & $<0.04$ & ns & ns & ns \\
\hline Bulimia & ns & $<0.01$ & ns & $<0.02$ \\
\hline Anorexia & ns & ns & ns & ns \\
\hline Smoking & ns & ns & ns & $<0.04$ \\
\hline Alcoholism & ns & ns & ns & ns \\
\hline Drug addiction & ns & ns & ns & ns \\
\hline
\end{tabular}

Table 8: Correlations between characteristics of sexual abuse and reported health disorders ( $p$ values; ns: $p>0.05$ ).

\section{Discussion}

The subjects participating in this study were an average of 42 years old and had their first sexual assault at an average age of 9 years, with an average duration of sexual abuse of 8 years. The first sexual abuse occurred before 11 years in about two-thirds of the respondents and only in $6.5 \%$ of them in adulthood.

They all agreed to answer the questionnaire proposed by their doctor; so they all had revealed the violence, even though the delay in self-disclosure was long, on average 11 years, which is common for victims of sexual violence [16]. It has also been reported that younger age at the time of abuse and experiencing a series of abuse were associated with longer disclosure latencies [17]. The fact that the response to the questionnaire occurred several years after the violence left enough time to assess its consequences on the health of the respondents.

Women accounted for $90 \%$ of respondents to the questionnaire; they suffered violence for periods on average twice as long as men; rape was reported by more than three quarters of participants in both women and men. More than $50 \%$ of the participants were victims of several aggressors, most of whom were men, although 19\% were subjected to assaults by aggressors of both sexes. This data is consistent with previous studies conducted in other countries showing that women are more often impacted, endure longer lasting violence and are predominantly victims of male perpetrators [18-21]. The survey data also confirmed that sexual violence starts most often during childhood and adolescence [22,23].
Chronic pain was reported by $66 \%$ of subjects and found more common among rape victims and those who had been assaulted by multiple perpetrators. Joint pain and muscle pain were the most frequently reported, followed by abdominal pain and headache/ migraine, both in men and women. These findings support the data of many reviews showing the association of sexual abuse with multiple types of pain, including musculoskeletal pain, backache, headache, abdominal pain, and pelvic pain [5-10].

Allergic conditions ranked second among the physical health disorders mentioned by participants, followed closely by skin conditions. This association has been much less noted in the literature, but might have not been questioned systematically. It is known that post-traumatic syndrome may influence immune function and promote delayed-type hypersensitivity [24].

In this series, $45 \%$ of women who have been sexually abused had a history of gynaecological disorders whose frequency is directly and significantly correlated with the severity of the violence, i.e. with its duration, the number of assaults and the number of perpetrators. It is well established that violence against women has an impact on reproductive health [25]. There is a close link between sexual abuse and chronic pelvic pain $[5,9]$. In addition, organic disorders can be induced by violence to women; for example, it may promote in adulthood the more frequent occurrence of uterine fibroma, as shown by two prospective cohort studies in female victims during childhood $[26,27]$. 
The frequency of other physical health disorders reported in the study, including that of gastrointestinal and neurological disorders, is consistent with the published data [12-14]; the high percentage of subjects reporting a history of ENT disorders is unusual, when compared to data from the literature. Nevertheless, ENT symptoms are not usually questioned systematically in most published studies.

Of all the disorders found in the medical history of the participants in this survey, depression came first; it was notified by $74 \%$ of the subjects who completed the questionnaire and was significantly correlated with the duration of sexual abuse and the number of perpetrators.

The mean HAD depression score at the time of filling out the questionnaire indicated an improvement in mood in most subjects, which is explained by the long delay since sexual abuse and certainly by the fact that many of the study participants had followed psychotherapy. Nevertheless, the mean HAD anxiety score remained high and indicated that anxiety is a sequel that persists long after the period of violence. Other psychological disorders usually associated with depression were also found with high prevalence, such as sleep disorders, claustrophobia, eating disorders, suicide attempts. More than one in three subjects ( $48 \%$ of women and $18 \%$ of men) made at least one suicide attempt with an average of five attempts; in this study, suicidal behavior was significantly higher in victims of rape and of multiple aggressors.

The psychiatric disorders of the subjects who responded to this survey are those usually reported by the victims of sexual violence but their prevalence is a little higher than that of published epidemiological studies $[1,2,4]$.

Because it has collected data from subjects who have accepted to answer a questionnaire this study is not representative of sexual violence in France because many victims do not agree to talk about the violence they have suffered. The sample does not allow comparison with a population of people who have never been sexually abused; it represents only victims willing to report their experience of sexual abuse.

The study also has the limitations common to retrospective surveys, and is subject to the possibility of recall bias since it is based on data that requires recall of lifetime traumatic events and symptoms subsequent to exposure to such trauma. Indeed, most published studies on the consequences of sexual violence to health are crosssectional and retrospective studies, with less power to assert a causal link. For example, the studies collected for the meta-analyses evaluating the effects of sexual abuse on physical health are almost all cross-sectional studies [11,12]. Longitudinal cohort studies have been more recently published, highlighting a higher risk of obesity, diabetes, hypertension and uterine fibroids in adult women who have been sexually abused in childhood or adolescence [26-29]. But these studies were all conducted in the United States on particular populations: female nurses and black women. In general, women are overrepresented in studies on the consequences of sexual abuse.

Our study, like many others has been conducted on a small sample. A lot of published data on the consequences of sexual violence on health come from meta-analyses, which have the advantage of gathering a large number of victims but brings together studies whose methodology and populations are different $[1,6,11,12]$. This survey focused on sexual abuse only unlike others which have taken into account other forms of violence: physical, psychological [3,8,12,26-29].
The characteristics of childhood sexual abuse involve memory, and data on pathologies, such as pain, are subjective and rarely quantified. For these reasons the modalities of data collection need to be discussed. A face-to-face or telephone interview would have resulted in more accurate information. In our study the use of a computer-assisted questionnaire did not make it possible to obtain clarification of the indications collected, but it had the advantage of preventing the responder from being influenced by the investigator while respecting anonymity and privacy.

\section{Conclusion}

In conclusion, this study, the first conducted in France, confirms data reported in other countries: Sexual violence is associated with a high prevalence of somatic and psychiatric disorders; they can affect all areas of medicine and occur throughout the lives of victims. Chronic pain, and gynaecological disorders, depression, sleep disorders and suicide attempts are among the most frequently reported disorders, most of them being significantly correlated to the severity of the violence. For the first time, a particularly high incidence of allergic dermatological and ENT disorders is highlighted in victims. Finally, this work shows that the disclosure latency is significantly longer for victims who were assaulted when they were younger.

\section{References}

1. Chen LP, Murad MH, Paras ML, Colbenson KM, Sattler AL, et al. (2010) Sexual abuse and lifetime diagnosis of psychiatric disorders: Systematic review and meta-analysis. Mayo Clin Proc 85: 618-629.

2. Chou KL (2012) Childhood sexual abuse and psychiatric disorders in middle-aged and older adults: Evidence from the 2007 Adult Psychiatric Morbidity Survey. J Clin Psychiatry 73: e1365-1371.

3. Safren SA, Gershuny BS, Marzol P, Otto MW, Pollack MH (2002) History of childhood abuse in panic disorder, social phobia, and generalized anxiety disorder. J Nerv Ment Dis 190: 453-456.

4. Pérez-Fuentes G, Olfson M, Villegas L, Morcillo C, Wang S, et al. (2013) Prevalence and correlates of child sexual abuse : A national study. Compr Psychiatry 54: 16-27.

5. Chandler HK, Ciccone DS, RaphaeL KG (2006) Localization of pain and self-reported rape in a female community sample. Pain Med 7: 344-352.

6. Davis DA, Luecken LJ, Zautra AJ (2005) Are reports of childhood abuse related to the experience of chronic pain in adulthood? A meta-analytic review of the literature. Clin J Pain 21: 398-405.

7. Spiegel DR, Shaukat AM, Mccroskey AL, Chatterjee A, Ahmadi T, et al. (2016) Conceptualizing a subtype of patients with chronic pain: The necessity of obtaining a history of sexual abuse. Int J Psychiatry Med 51:84-103.

8. Boisset-Pioro MH, Esdaille JM, Fitzcharles MA (1995) Sexual and physical abuse in women with fibromyalgia syndrome. Arthritis Rheum 38: 235-241.

9. Walker E, Katon W, Harrop-Griffiths J, Holm L, Russo J, et al. (1988) Relationship of chronic pelvic pain to psychiatric diagnoses and childhood sexual abuse. Am J Psychiatry 145: 75-80.

10. Golding JM (1999) Sexual assault history and headache: Five general population studies. J Nerv Ment Dis 187: 624-629.

11. Paras ML, Murad MH, Chen LP, Goranson EN, Sattler AL, et al. (2009) Sexual abuse and lifetime diagnosis of somatic disorders: A systematic review and meta-analysis. JAMA 302: 550-561.

12. Wegman HL, Stetler C (2009) A meta-analytic review of the effects of childhood abuse on medical outcomes in adulthood. Psychosom Med 71: 805-812.

13. Leserman J (2005) Sexual abuse history: Prevalence, health effects, mediators, and psychological treatment. Psychosom Med 67: 906-915. 
Citation: Thomas JT, Guérin V, Lévy P, Carette M, de Andreis NR, et al. (2017) The Impact of a History of Sexual Abuse on Health: Data from a Self-Reported Questionnaire from a Sample of French Victims. J Gen Pract (Los Angel) 5: 340. doi:10.4172/2329-9126.1000340

Page 8 of 8

14. Walker EA, Gelfand AN, Gelfand MD, Koss MP, Katon WJ (1995) Medical and psychiatric symptoms in female gastroenterology clinic patients with histories of sexual victimization. Gen Hosp Psychiatry 17: 85-92.

15. Zigmond AS, Snaith RP (1983) The hospital anxiety and depression scale. Acta Psychiatr Scand 67: 361-370.

16. Tener D, Murphy SB (2015) Adult disclosure of child sexual abuse: A literature review. Trauma Violence Abuse 16: 391-400.

17. Smith DW, Letourneau EJ, Saunders BE, Kilpatrick DG, Resnick HS, et al. (2000) Delay in disclosure of childhood rape: Results from a national survey. Child Abuse Negl 24: 273-87.

18. Breiding MJ, Smith SG, Basile KC, Walters ML, Chen J, et al. (2014) Prevalence and characteristics of sexual violence, stalking, and intimate partner violence victimization: National intimate partner and sexual violence survey, United States, 2011. MMWR Surveill Summ 63: 1-18.

19. Tjaden PG, Thoennes N (2001) Coworker violence and gender. Findings from the National Violence Against Women Survey. Am J Prev Med 20:85-89.

20. Nybergh L, Taft C, Enander V, Krantz G (2013) Self-reported exposure to intimate partner violence among women and men in Sweden: Results from a population-based survey. BMC Public Health 13: 845.

21. Krahe B, Berger A, Vanwesenbeeck I, Bianchi G, Chliaoutakis J, et al (2015) Prevalence and correlates of young people's sexual aggression perpetration and victimisation in 10 European countries: A multi-level analysis. Cult Health Sex 17: 682-699.

22. Rickert VI, Wiemann CM (1998) Date rape among adolescents and young adults. J Pediatr Adolesc Gynecol 11: 167-175.

23. Murray LK, Nguyen A, Cohen JA (2014) Child sexual abuse. Child Adolesc Psychiatr Clin N Am 23: 321-337.

24. Altemus M, Dhabhar FS, Yang R (2006) Immune function in PTSD. Ann N Y Acad Sci 1071: 167-183.

25. Golding JM, Wilsnack SC, Learman LA (1998) Prevalence of sexual assault history among women with common gynecologic symptoms. Am J Obstet Gynecol 179: 1013-1019.

26. Boynton-Jarrett R, Rich-Edwards JW, Jun HJ, Hibert EN, Wright RJ (2011) Abuse in childhood and risk of uterine leiomyoma: The role of emotional support in biologic resilience. Epidemiology 22: 6-14

27. Wise LA, Palmer JR, Rosenberg L (2013) Lifetime abuse victimization and risk of uterine leiomyomata in black women. Am J Obstet Gynecol 208: 272-272.

28. Mason SM, Wright RJ, Hibert EN, Spiegelman D, Jun HJ, et al. (2013) Intimate partner violence and incidence of type 2 diabetes in women. Diabetes Care 36: 1159-1165.

29. Riley EH, Wright RJ, Jun HJ, Hibert EN, Rich-Edwards JW (2010) Hypertension in adult survivors of child abuse: Observations from the Nurses' Health Study II. J Epidemiol Community Health 64: 413-418. 